\title{
Impact of Reclamation Project on Mercury-Contaminated Sediment Transport from Minamata Bay into the Yatsushiro Sea
}

\author{
Edistri Nur FATHYA ${ }^{1}$, Shinichiro YANO ${ }^{2}$, Akito MATSUYAMA ${ }^{3}$, Akihide TADA ${ }^{4}$, \\ and Herawaty RIOGILANG ${ }^{5}$ \\ ${ }^{1} \mathrm{Ph} . \mathrm{D}$ Student, Dept. of Maritime Engineering, Kyushu University \\ (744 Motooka, Nishi-ku, Fukuoka, 819-0395, Japan) \\ E-mail:edisfathya@gmail.com \\ ${ }^{2}$ Member of JSCE, Professor, ditto, E-mail:yano@ civil.kyushu-u.ac.jp \\ ${ }^{3}$ Member of JSCE, Chief, Mercury Analysis Technique Section, National Institute for Minamata Disease \\ (4058-18 Hama, Minamata, Kumamoto, 867-0008, Japan) \\ ${ }^{4}$ Member of JSCE, Professor, Graduate school of Engineering, Division of System Science, Nagasaki University \\ (1-14 Bunkyo-cho, Nagasaki, 852-8521, Japan) \\ ${ }^{5}$ Sam Ratulangi University, Lecturer, Faculty of Engineering, North Sulawesi, Indonesia \\ (JL. Kampus Unsrat Bahu, North Sulawesi, Indonesia)
}

\begin{abstract}
Minamata Bay which suffered from a major disaster called "Minamata Disease" has already remediated from 1977 to 1990 by carried out highly mercury $(\mathrm{Hg})$ contaminated sediment and reclaimed it in the bay area. Furthermore, many studies reported that the mercury has reached Yatsushiro Sea, the outer part of Minamata Bay. It can be assumed that the sediment transport still occurs from remaining $\mathrm{Hg}$ concentration even after the remediation project. In order to investigate it, we try to simulate the transport of sediment contaminated by $\mathrm{Hg}$ from Minamata Bay to the Yatsushiro Sea with different coastal morphology on before and after the reclamation projects.

Sediment transport and tidal flow with rectangular variable grid both before and after reclamation conditions around the Yatsushiro Sea and Minamata Bay are simulated by DELFT3D. The initial bottom sediment thickness of $1 \mathrm{~m}$ is set in the only inner side of the bay and six months simulation results for both before and after reclamation area are compared. The change of hydrodynamic condition inside Minamata Bay due to the remediation project gives a slight change in sediment transport pattern. It is estimated that after the reclamation, the sediment transport moves slower than before it due to the change of its magnitude of velocity above the seabed. As an important result, it is clarified that a change of the amount of bottom sediment which can be re-suspended in Minamata Bay caused by the topographical change can also affect the pattern. Also, this result suggests that the southern part of Yatsushiro Sea can be influenced by sediment contaminated by higher $\mathrm{Hg}$ included before the reclamation project.
\end{abstract}

Key Words : Minamata Bay, sediment transport, reclamation, mercury, Yatsushiro Sea

\section{INTRODUCTION}

Minamata Bay is known by its huge anthropogenic disaster called "Minamata Disease" which caused by mercury $(\mathrm{Hg})$ compound that disposed from a chemical factory from 1932 through $1968^{1)}$. The disposed compound was methylmercury (MeHg) compound generated in the factory process which mostly deposited in seabed as sediment ${ }^{2}$. This $\mathrm{MeHg}$ compound can accumulate in fish or other sea creatures and in the end, in human due to consumption of them. Human contaminated by a large amount of mercury, after several years, showed a strange symptom such as a difficulty of walking and speaking. Later, the disease was known as the Minamata Disease which attacks the central nervous system ${ }^{1}$. It was reported in 2010 , more than 40,000 people have been identified to have partial symptoms of Minamata Disease and all of them had received medical support from the government ${ }^{3)}$. As of the end of May 2013, the number of certified patients from Kumamoto and Kagoshima Prefecture was 2,275 and around 460 of them were still alive ${ }^{4)}$.

The remediation project for reducing mercury 
concentration around Minamata Bay had already conducted from 1977 to 1990 . The project was carried out in over around $2.1 \mathrm{~km}^{2}$ bay area. Suction-dredging of about 1.5 million ton bottom sediments which were contaminated by high total mercury with more than $25 \mathrm{ppm}$ (dry weight) and reclamation in $0.58 \mathrm{~km}^{2}$ enclosed bay area by deposition of the sediments were conducted ${ }^{1)}$. The maximum concentration of total $\mathrm{Hg}$ in the sediments around Minamata Bay has been reduced significantly from $2,700 \mathrm{ppm}$ before dredging to $8.85 \mathrm{ppm}$ after dredging $^{5)}$. In 2012, 25 years later after the remediation project, Matsuyama et al. (2014) reported that total $\mathrm{Hg}$ concentration in the sediments around the bay was $2.96 \mathrm{ppm}^{6}$.

Furthermore, many studies reported that the mercury has reached the Yatsushiro Sea, which is the outer part of Minamata Bay. Based on Rajar et al. (2004), contaminated area has reached the Yatsushiro Sea, mostly before, or during the dredging process ${ }^{7}$. Rifardi et al., (1998) also reported based on their field survey result, there were southern and northern sediment transports that contained mercury in Yatsushiro Sea ${ }^{8)}$. Recently, Snyder $(2012)^{9)}$ mentioned that the Asahi Shinbun reported that between January 2005 and June 2010 around 568 people who live in the designated area for relief measures in Amakusa region, the western part of Yatsushiro Sea, plus 160 people who live outside of the designated area have shown similar symptoms with Minamata Disease patients ${ }^{9}$.

Another evidence of mercury transport from Minamata Bay to the Yatsushiro Sea was reported by Nakata et al. $(2008)^{10)}$. They observed in the Yatsushiro Sea, the background $\mathrm{Hg}$ concentration in sediment from $0.1 \mathrm{ppm}$ has increased to more than 0.4 ppm, especially in the southern part of Yatsushiro $\mathrm{Sea}^{10)}$. By those reports above, it can be assumed that the sediment transport still occurs from remaining $\mathrm{Hg}$ concentration in Minamata Bay to the Yatsushiro Sea even after the dredging and reclamation projects.

The investigation into this incident will be con-

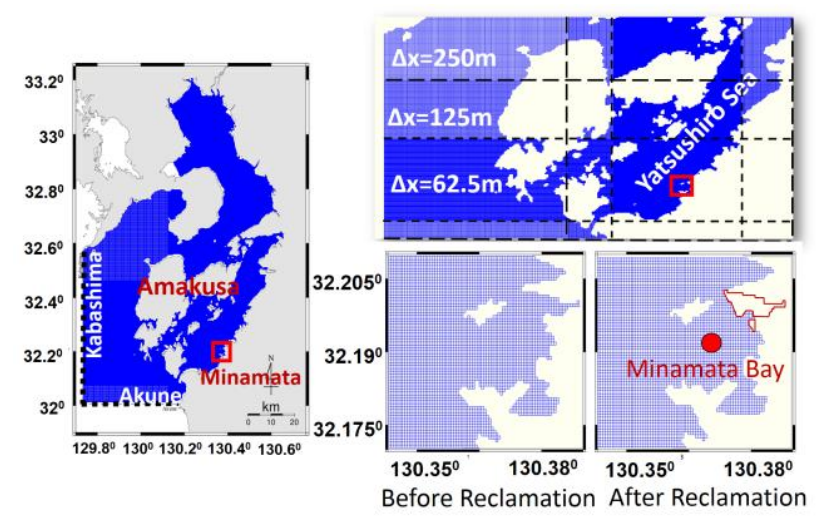

Fig.1 Computational domain, variable grid system and topography around Minamata Bay before and after reclamation. ducted by numerically simulating the transport of sediment contaminated by $\mathrm{Hg}$ from Minamata Bay to the Yatsushiro Sea with different coastal morphology before and after the reclamation projects around Minamata Bay. From both numerical simulations, we are expecting to see the pattern of sediment transport in each condition and its differences, and finally, we can estimate the cause of sediment transport which still occur even after the reclamation project from Minamata Bay to the Yatsushiro Sea.

\section{MODEL DESCRIPTION}

The simulations of hydrodynamics and sediment transport around Minamata Bay are similar to the previous study by Yano et al. $(2014)^{11)}$. Most of the model parameters, calculation, and simulation time are adapted from that study. Furthermore, in this study, we use a different grid system and also we add the before and after reclamation topography to compare the pattern of hydrodynamics and sediment transport in each condition.

\section{(1) Computational domain and grid system}

The western part of Kyushu Island is our concerning area where the Yatsushiro Sea and Minamata Bay are located. Yatsushiro Sea is a semi-enclosed sea area, which connects to the East China Sea in the southern part. In order to minimize error due to the boundary condition, a larger area of simulation is used. Computational domain of the model includes both of the Ariake Sea and the Yatsushiro Sea (Fig.1) and the concerned area is the southern part of the Yatsushiro Sea including Minamata Bay (red box in Fig.1).

The rectangular variable grid both before and after reclamation conditions are made by grid module in DELFT3D software, each grid consists of three different grid sizes, namely, $250 \mathrm{~m}$ (original size in Yano et al., $\left.(2014)^{11)}\right), 125 \mathrm{~m}$, and the finest $62.5 \mathrm{~m}$ including Minamata Bay in it (Fig.1). On the after reclamation condition, land reclamation area is added inside the red line (Fig.1). In addition, we use 5 layers in $\sigma$-coordinate system vertically as the same layer number with the previous simulation ${ }^{11)}$.

\section{(2) Numerical Model}

The numerical simulation of hydrodynamic uses DELFT3D in a three-dimensional coastal area. In addition to the hydrodynamic model, DELFT3D also includes sediment transport model, morphological model, ecosystem model, wave model, and so on. Therefore, in this study, the sediment transport simulation also used DELFT3D by adapting the moving wall boundary model for tidal flat areas. The hori- 
zontal eddy viscosity is evaluated by the sub-grid scale (SGS) model and vertical eddy viscosity is evaluated by $k-\varepsilon$ turbulent model including buoyancy effect terms. Based on Yano et al. (2014) ${ }^{11)}$, the erosion and deposition processes of bottom sediment use the Ariathrai-Patheniades equation and Krone's equation (Equations (1) and (2)).

$$
\begin{aligned}
& E=\left\{\begin{array}{c}
M\left(\frac{\tau_{b}}{\tau_{c r, e}}-1\right): \tau_{b}>\tau_{c r, e} \\
0: \tau_{b} \leq \tau_{c r, e}
\end{array}\right. \\
& D=\left\{\begin{array}{c}
w c_{b}\left(1-\frac{\tau_{b}}{\tau_{c r, d}}\right): \tau_{b}<\tau_{c r, d} \\
0 \quad: \tau_{b} \geq \tau_{c r, d}
\end{array}\right.
\end{aligned}
$$

where, $E$ : erosion flux $\left(\mathrm{kg} / \mathrm{m}^{2} / \mathrm{s}\right), M$ : erosion parameter $\left(\mathrm{kg} / \mathrm{m}^{2} / \mathrm{s}\right), D$ : deposition flux $\left(\mathrm{kg} / \mathrm{m}^{2} / \mathrm{s}\right)$, w: settling velocity $(\mathrm{m} / \mathrm{s}), c_{b}$ : suspended solid (SS) concentration in the bottom layer $\left(\mathrm{kg} / \mathrm{m}^{3}\right), \tau_{b}$ : bottom shear stress $\left(\mathrm{N} / \mathrm{m}^{2}\right), \tau_{c r, e}$ : critical bottom shear stress for erosion, and $\tau_{c r, d}$ : critical bottom shear stress for deposition.

\section{(3) Boundary conditions and model parameters}

The open boundary is set as a line from Akune to Kabashima (Fig.1). 40 tidal components, with 2 major components, $\mathrm{M}_{2}$ and $\mathrm{S}_{2}$, which were obtained from observation data are used as the open boundary condition to consider the fortnightly change of tide. The harmonic constants were calibrated from the measurement result of the tide at several tide gauge stations by Yano et al. $(2010)^{12)}$. The initial bottom sediment thickness of $1 \mathrm{~m}$ is set in the only inner side of the bay. Here, horizontal distribution of cumulative deposition thickness of sediment can be considered as a horizontal pattern of total $\mathrm{Hg}$ in bottom sediment $^{11)}$.

Model parameters for erosion and deposition processes are based on the study by Yano et al. $(2014)^{11)}$. They used Nakagawa and Yoshida ${ }^{13)}$ values for the parameters: i.e., $w=0.0018 \mathrm{~m} / \mathrm{s}, M=3.3 \times 10^{4} \mathrm{~kg} / \mathrm{m}^{2} / \mathrm{s}$, and $\tau_{c r, d}=1.0 \quad \mathrm{~N} / \mathrm{m}^{2}$. They considered that re-suspension of bottom sediment occurs in Minamata Bay where tidal current is weak normally, so they set the $\tau_{c r, e}$, in small value $0.001 \mathrm{~N} / \mathrm{m}^{2}$.

The initial one month calculation was conducted as a preliminary calculation for eliminating the effect of the initial condition of tidal currents which was static. The six month simulation was conducted to represent the sediment transport in the Yatsushiro Sea. The hydrodynamic result is validated with observation data obtained from Water Information System by Japan Ministry of Land, Infrastructure, Transport, and Tourism (MLIT) (http://www1.river.go.jp), and the horizontal distribution of cumulative sediment is validated by measured data from Rifardi et al.
$(1998)^{8)}$. But here, regardless the mercury concentration, we only consider to the similarity of the pattern and direction of the sediment transport around Minamata Bay and in the Yatsushiro Sea.

\section{VALIDATION OF SIMULATIONS}

\section{(1) Validation of water level}

The validation of water level and tidal ellipse have been conducted in the previous study by Yano et al $(2010)^{12)}$. They compared the water level and tidal ellipse at certain points with field measurement data. Considering the difference of grid system, the validation of water level here is only additional validation from that which have been done by Yano et al. $(2010)^{12)}$. We use hourly water level data in the Midori River and the Kuma River estuaries from the Water Information System of MLIT (red triangle in Fig.2). These points still can be considered as valid data for comparison because both river estuaries are still in the range of simulation area.

Figure 2 shows two water level data including one fortnightly variation of the tide for about 15 days, from January 11th to 26th, 2003 (red points). These observation data are compared with simulation result also in Midori and Kuma River mouth points at the same time (blue solid line). The observed data and simulation result in each point show a similar range and phase of the tide.

\section{(2) Validation of horizontal distribution of cu- mulative sediment}

Horizontal distribution of cumulative sediment is validated by measured data from Rifardi et al. $(1998)^{8)}$. They conducted sediment core sampling in the Yatsushiro Sea, resulting horizontal distribution of maximum total $\mathrm{Hg}$ concentration in bottom sediment. Based on their research, the contaminated sediment was transported both northeastward and southward by longshore current and spread north and west across the sea in the northern and southern parts of Yatsushiro Sea ${ }^{8}$.

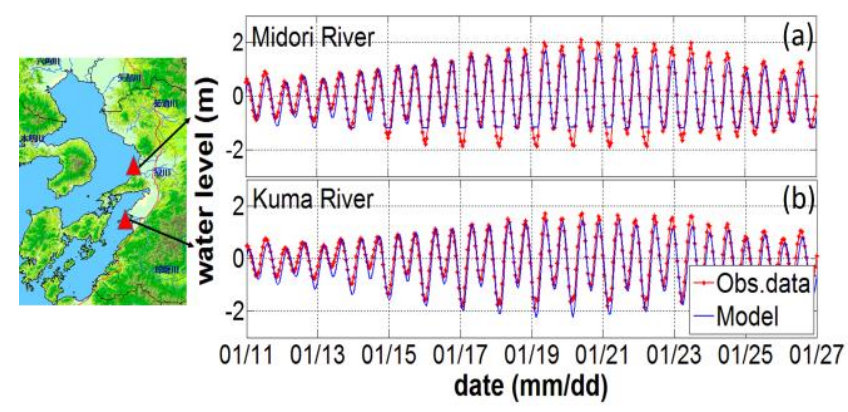

Fig.2 Water level validation at (a) Midori River and (b) Kuma River point. [Unit: $\mathrm{m}$ ] 
The results from our simulation both for before and after reclamations in 30 days show the sediment transport move almost to all over the Yatsushiro Sea. There are southward, westward, and northward transports instead of northeastward as reported by Rifardi et al. (1998). This difference because here we only do the simulation by barotropic conditions and not consider the baroclinic flow which can cause both the north and northeast transports ${ }^{11)}$. In addition, the similarity is also shown by comparing these results with the calculation result by Tai and Yano $(2007)^{14)}$. Their study showed that the particle tracking method in 2D depth-averaged model by barotropic tidal forcing in which tracers initially released into the Minamata Bay could spread over the whole area of the Yatsushiro Sea for one month.

Actually, those similarities do not imply that this model can represent actual sediment transport phenomena from Minamata Bay to the Yatsushiro Sea including the Amakusa region because of limited data and information about it. However, this simulation can be expected as a description about how the distribution of sediment containing mercury from Minamata Bay can reach the western, southern, and northern part of Yatsushiro Sea.

\section{RESULT AND DISCUSSION}

\section{(1) Hydrodynamic conditions in before and after} reclamation cases

The horizontal velocity above seabed (layer 5) in Minamata Bay in before and after reclamation cases in the maximum spring tide are shown in Fig.3 and Fig.4, respectively. Low velocity is indicated by blue color and high velocity is red. In before reclamation case, at low tide and high tide (Figs.3(a) and 3(c)), when the current velocity in minimum phase, the values are almost zero. On the contrary, at flood tide and ebb tide (Figs.3(b) and 3(d)), tidal currents are in maximum speed. We can see the difference in the mouth of the bay (red circle), where at flood tide, current velocity is around $0.02-0.04 \mathrm{~m} / \mathrm{s}$ and at ebb tide is higher than flood tide, exceeding $0.06 \mathrm{~m} / \mathrm{s}$. It means that tidal current which moves toward the outside of Minamata Bay is higher than the one that moves towards the inside of bay. In other words, re-suspended sediments in the bay within a certain period will definitely be transported to the outer side of the bay, namely the Yatsushiro Sea.

The plot of horizontal velocity above seabed on after reclamation case is at the same time with before reclamation case, and it is shown in Fig.4. At low tide and high tide (Figs. 4(a) and 4(c)) in the bay, horizontal velocities are minimum, otherwise, at flood and ebb tide are maximum (Figs. 4(b) and 4(d)). In the inner side of the bay, the horizontal velocity is around $0-0.02 \mathrm{~m} / \mathrm{s}$ for flood tide and 0.03 $\mathrm{m} / \mathrm{s}$ for ebb tide. The results at the ebb and flood tides for before reclamation (Figs. 3(b) and 3(d)) show higher current magnitude (the light blue and green color) than after reclamation one (Figs. 4(b) and 4(d)). Therefore, it can be expected that the remediation project changes the hydrodynamic condition around Minamata Bay. This situation also can change the magnitude of bottom sediment transport from Minamata Bay to the outer side of the bay.

\section{(2) Bottom sediment transport in before and after reclamation cases}

The simulation result of cumulative deposition and erosion thickness after 5, 30, and 180 days for before
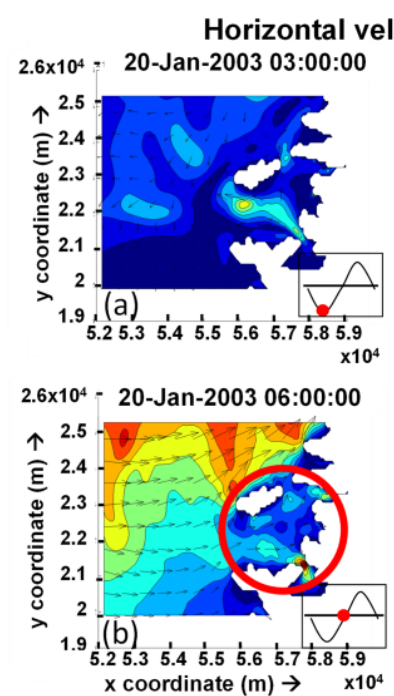
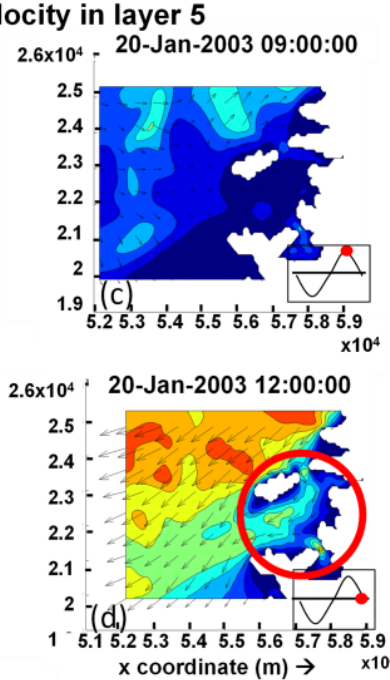

Fig.3 Horizontal velocity above seabed at (a) low tide, (b) flood tide, (c) high tide and (d) ebb tide before the reclamation project. [Unit: $\mathrm{m} / \mathrm{s}$ ]

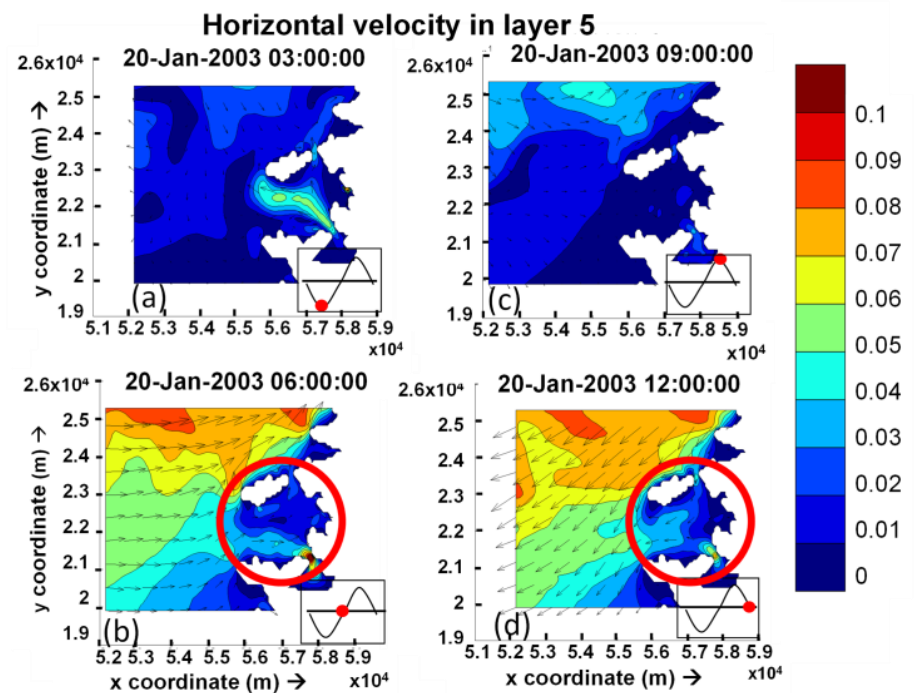

Fig.4 Horizontal velocity above seabed at (a) low tide, (b) flood tide, (c) high tide and (d) ebb tide after the reclamation project. [Unit: $\mathrm{m} / \mathrm{s}$ ] 


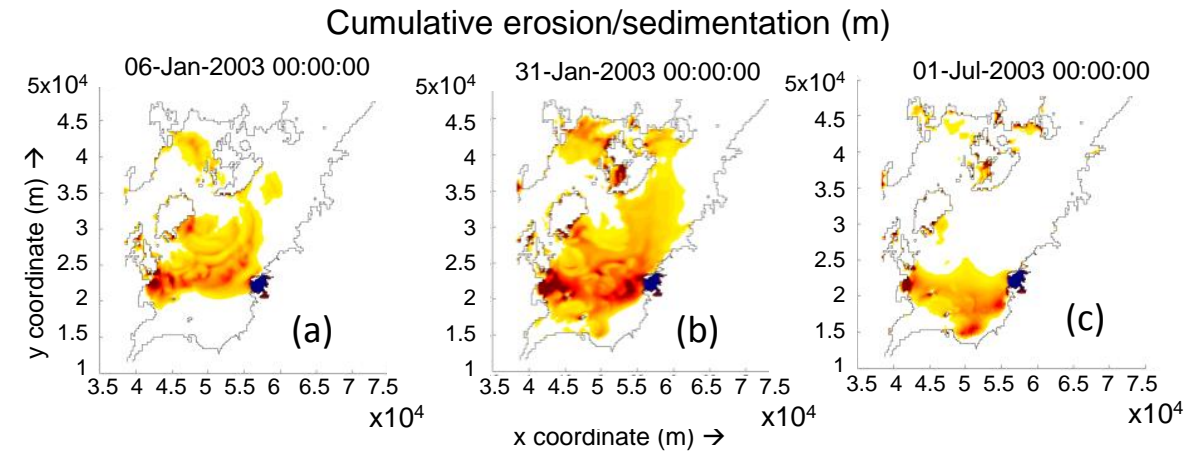

Fig.5 Cumulative deposition and erosion thickness distribution before the reclamation project after (a) 5 days, (b) 30 days, and (c) 180 days. [Unit: $\mathrm{m}$ ]

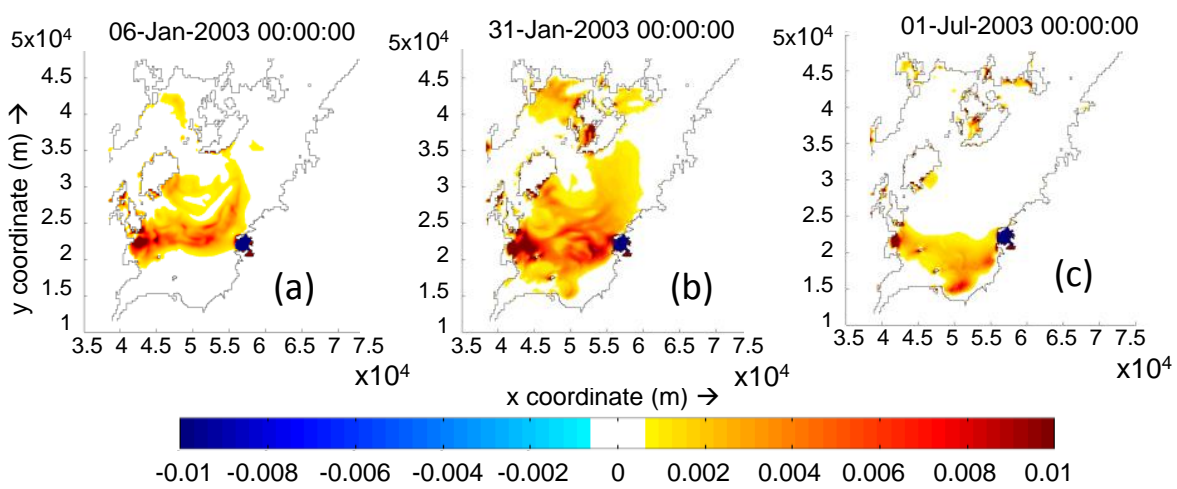

Fig.6 Cumulative deposition and erosion thickness distribution after the reclamation project after (a) 5 days, (b) 30 days, and (c) 180 days. [Unit: $\mathrm{m}$ ]

and after the reclamation project are shown in Fig.5 and Fig.6, respectively. Red color indicates sedimentation and blue color is erosion. In before reclamation case, after 5 days (Fig.5(a)), mostly bottom sediment in Minamata Bay is eroded and transported to the west and north part of the Yatsushiro Sea. After 30 days (Fig.5(b)), bottom sediment transport moves not only westward and northward but also southward. Finally, after 180 days (Fig.5(c)), the northward transport is reduced, resulting a slight northern transport and most of the rest of sediment in Minamata Bay is deposited in the southern and western part of the Yatsushiro Sea.

Similar to before reclamation case, for after reclamation, sediment transport after 5 days moves westward and northward (Fig.6(a)), and after 30 days, the sediment is transported to almost all of the Yatsushiro Sea, namely, westward, southward, and northward (Fig.6(b)). Finally, after 180 days, the sediment is deposited in the western and southern part of the Yatsushiro Sea (Fig.6(c)). There is no sign of northward transport as seen in Fig.5(c) on before reclamation case. Here, we also can assume that the horizontal barotropic flow above seabed in the Yatsushiro Sea is mostly moving southward from Minamata Bay.

In before reclamation case on 5 and 30 days (Figs.5(a) and 5(b)), sediments seem slightly more widespread than in after reclamation case (Figs.6(a) and 6(b)). Meanwhile after 180 days, as mentioned above, in before reclamation case (Fig.5(c)), there is a small northern transport in the Yatsushiro Sea which is not visible in after reclamation case (Fig.6(c)). Those situations can be caused by two factors, in before reclamation case, the velocity above seabed is higher than after reclamation as seen in Fig.3(d), and the area of initial sediment in Minamata Bay is larger than after reclamation case.

From both conditions, it can be assumed that the slight change of hydrodynamic conditions caused by the reclamation project in Minamata Bay also affects the bottom sediment transport from Minamata Bay to the Yatsushiro Sea. After the reclamation, the bottom sediment transport moves slower due to the small change of the horizontal velocity above the seabed. Actually, this small change does not give a significant effect to the mercury distribution in the Yatsushiro Sea, therefore, this situation can be the cause of impermanent increasing of mercury concentration in Amakusa region that suggests the possibility of generation of Minamata Disease in the region. But, we cannot show conclusive results because of the uncertainty of model parameters, especially critical shear stress. So, determination of those unknown parameters from field survey is urgently required. Also by this result, it means that the increasing $\mathrm{Hg}$ concentration in the Yatsushiro Sea also occurred in before reclamation time and the remaining mercury 
in bottom sediments of Minamata Bay can also still transported to the Yatsushiro Sea. From the perspective of risk management for human and marine organisms' life, it is important to keep the bottom sediments in Minamata Bay on the low concentration of $\mathrm{Hg}$. That situation is in order to prevent the higher $\mathrm{Hg}$ concentration caused by the leakage of reclaimed sediment which is including extremely high $\mathrm{Hg}$ concentration from reclaimed area to the bay.

\section{CONCLUSIONS}

Comparing two conditions before and after reclamation, lead us to some conclusions regarding the hydrodynamic and bottom sediment transport condition in Minamata Bay as follows:

1. Sediment transport from the inner side of Minamata Bay into the Yatsushiro Sea is intense when ebb tide occurs, which moves the sediments toward the Yatsushiro Sea, then barotropic flow moves the sediments mostly to the westward and southward.

2. The change of the coastal topography on after the reclamation project makes a slight change to the hydrodynamic conditions around Minamata Bay where horizontal tidal current above seabed become weaker than before it.

3. The change of the magnitude of horizontal velocity above seabed inside Minamata Bay also makes the sediment transport after reclamation moves slower than before it.

As an important result, it is clarified that a change of the amount of bottom sediment which can be re-suspended in Minamata Bay caused by the topographical change can also affect the pattern. Also, this result shows that the southern part of Yatsushiro Sea may be influenced by sediment contaminated by higher $\mathrm{Hg}$ included before the reclamation project.

This study is still in development with many shortcomings that must be completed, such as longer simulation and additional parameters for river discharge, as well as the exact critical shear stress and mercury concentration in Minamata Bay for the initial condition which should be inputted to achieve a more accurate result. Further, an advanced study including in-situ methylation and demethylation process should be applied to investigate the mercury dynamics in sediment and seawater especially for the fate of methylmercury compound in the marine environment.

ACKNOWLEDGMENT: The study was supported by JSPS KAKENHI Grant Number 24360200.

\section{REFERENCES}

1) Balogh, S. J., Tsz-Ki Tsui, M., Blum, J.D., Matsuyama, A., Woerndle, G.E., Yano, S. and Tada. A.: Tracking the fate of mercury in the fish and bottom sediments of Minamata Bay, Japan, using stable mercury isotopes, Environ. Sci. Technol., Vol.49, No.9, pp.5399-5406, 2015.

2) Zagar, D., Knap, A., Warwick, J.J., Rajar, R. and Horvat, M.: Modelling of mercury transport and transformations in the water compartment of the Mediterranean Sea, Marine Chemistry, Vol.107, pp.64-88, 2007.

3) Hachiya, N.: Epidemiological update of methylmercury and Minamata Disease, In Methylmercury and Neurotoxicity, Current Topics in Neurotoxicity 2 (Ceccatelli, S., Aschner, M., eds.), Springer, New York, pp.1-11, 2012.

4) Ministry of Environment, Japan: Lessons from Minamata Disease and mercury management in Japan, Environmental Health and Safety Division, Environmental Health Department, Ministry of Environment, Japan, 2013.

5) Tomiyasu, T., Matsuyama, A., Egushi, T., Fuchigami, Y., Oki, K., Horvat, M., Rajar, R. and Akagi, H.: Spatial variations of mercury in sediment of Minamata Bay, Japan, Sci. Total Environ., Vol.369, pp.283- 290, 2006.

6) Matsuyama, A., Yano, S., Hisano, A., Kindaichi, M., Sonoda, I., Tada, A. and Akagi, H.: Reevaluation of Minamata Bay, 25 years after the dredging of mercury-polluted sediments, Marine Pollution Bulletin, Vol.89, pp.112-120, 2014.

7) Rajar, R., Zagar, D., Cetina, M., Akagi, H., Yano, S., Tomiyasu, T. and Horvat, M.: Application of three dimensional mercury cycling model to coastal seas, Ecological Modeling, Vol.171, pp.139-155, 2004.

8) Rifardi, Oki, K. and Tomiyasu, T.: Sedimentary environment based on textures of surface sediments and sedimentation rates in the South Yatsushiro Kai (Sea), southwest Kyushu, Japan, Journal of Sedimentological Society of Japan, Vol.48, pp.67-84, 1998.

9) Snyder, S.: News from around the world, Report: Minamata Disease likely not restricted to designated relief areas, Glob Adv Health Med., Vol.1, No.3, pp.14-15, 2012.

10) Nakata, H., Shimada, H., Yoshimoto, M., Narumi, R., Akimoto, K., Yamashita, T., Matsunga, T., Nishimura, K., Tanaka, M., Hiraki, K., Shimasaki, H., and Takikawa, K.: Concentrations and distribution of mercury and other heavy metals in surface sediments of the Yatsushiro Sea including Minamata Bay, Japan, Bull. Environ. Contam. Toxicol, Vol.80, pp.78-84, 2008.

11) Yano, S., Kawase, H., Hisano, A., Riogilang, H., Tada, T. and Matsuyama, A.: The effect of salinity stratification on sediment transport in Minamata Bay, Proceeding of the 19th IAHR-APD Congress 2014, in USB memory, 2014.

12) Yano, S., Winterwerp, J.C., Tai, A. and Saita, T.: Numerical experiments on features of nonlinear tide and its influences on sediment transport in the Ariake Sea and Yatsushiro Sea, Journal of JSCE, Sr. B2 (Coastal Engineering), Vol.66, No.1, pp.341-345, 2010. (In Japanese with English abstract)

13) Nakagawa, Y and Yoshida, H.: Field observation and modeling of suspended fine sediment load in Ariake By, Japan. Sediment and Ecohydraulics: INTERCOH 2005, Proc. Of Marine Science, Vol.9, pp. 155-163, 2008.

14) Tai, A. and Yano, S.: Numerical analysis of characteristics of tide and tidal current in the Yatsushiro Sea. Annual Journal of Civil Engineering in the Ocean, JSCE, Vol.23, pp.603-608, 2007. (In Japanese with English abstract)

(Received March 16, 2016) 